\title{
Cog-Motivational Factors as Correlates of Academic Learned Helplessness Among Secondary School Students in Rivers State
}

\author{
Nwanze, Rita. Chinenye Dr. Opara, Ijeoma Margaret \\ Department of Educational Psychology, Guidance \& Counseling, University of Port Harcourt, \\ Rivers State, Nigeria.
}

\begin{abstract}
The study investigated cog-motivational (cognitive \& motivational) as correlates of academic learned helplessness among secondary school students in Rivers state. Cog-motivational factors of (self-efficacy, attribution and achievement motivation), were the independent variables while academic learned helplessness was the dependent variable. Four research questions and four null hypotheses guided the study. A sample of 500 SS2 academic learned helplessness students was drawn from a population of 32,126 SS2 students in public secondary schools in Rivers State, using multi-stage sampling procedure. Two instruments were used for the study: Cog-motivational Factors Scale (CFS) and Academic Learned Helplessness Scale (ALHS). Data collected were analyzed using simple and multiple regression statistics. Results of the study indicated that cog-motivational factors of (self-efficacy, attribution and achievement motivation) jointly, had a low positive relationship with academic learned helplessness which was significant at 0.05 levels of significance. Independently, self-efficacy had a negative relationship with academic learned helplessness, while attribution and achievement motivation had positive relationships with academic learned helplessness. Statistical testing revealed that independently, attribution had a significant relationship with academic learned helplessness while self-efficacy and achievement motivation had no significant relationship with academic learned helplessness. Based on the findings appropriate recommendations were made among which is that guidance counsellors should be employed in all public secondary schools in Rivers State to assist students with the problem of academic learned helplessness to improve academic performance
\end{abstract} Keywords: Self-efficacy, Attributon, Achievement motivation and Academic Learned Helplessness DOI: $10.7176 /$ RHSS/9-8-01

Publication date: April $30^{\text {th }} 2019$

\section{Introduction}

The feeling of helplessness is a severe problem that affects people in different areas of endeavor and needs to be fixed. This helpless feeling is associated with a lot of other psychological problems, such as anxiety, low selfesteem, lack of motivation, phobia and even depression (Ekeh \& Nwanze, 2015). When this helpless feeling continue to occur in respect to any adverse environment people often develop a condition known as learned helplessness. Learned helplessness is defined as a condition arising from traumatic event or persistent failure to succeed in a particular task. It is a condition resulting from the perception that we have no control over our environment. It is described as the helplessness and resignation learned when a human perceives no control over repeated bad events; a condition resulting from the perception that one has no control over one's environment (Schultz \& Schultz, 2005). It is seen as the belief that one's outcomes are independent of one's actions (Durkin, 1995). Cherry (2014), described learned helplessness as giving up attitude, as expectations of future non contingency (outcomes no longer depend on actions), believing it won't matter whatever one does, believing that one has no control over an outcome of an event, and believing that one's actions are futile. When this feeling is experienced in academics, is described as academic learned helplessness.

In Rivers state, it has been observed that many students have this problem of learned helplessness in their academics despite the large of academic institutions scattered all over the state. However the researchers decided to investigate cog- motivational factors in relation to academic learned helplessness among secondary school students in Rivers state. The cog-motivational factors investigated include self-efficacy, attribution and achievement motivation.

The problem of learned helplessness behavior in academics is a very serious educational problem that needs to be fixed. This problem of learned helplessness in academics consequently has resulted in academic and school failures, in one way or the other. In effect, most students try to avoid those subjects in which they experience learned helplessness. Children who have developed learned helplessness are at serious risk for negative affect, negative expectations, decreased performance and also avoidance of challenging tasks. However, every child deserves to learn well. It is important that students that are learned helpless in academics are being carried along with others.

Over the years, it has been observed that academic achievement of students, especially those of learned helpless students, has continued to decline. It is imperative to note that failure in academics does not only affect the students alone as a person, but also affects the larger society. This implies that when students do not do well in academics, they will come out half-baked or empty to the society, thereby contributing less or nothing to the 
productivity of the society at large. Also decline in academic achievement affects the progress of scientific and technological advancements in the society.

With these reasons, it becomes necessary to explicate the nature and characteristics associated with learned helplessness and determine the extent to which cog-motivational factors may relate with it, among secondary school students. The problem of this study therefore, is to investigate the extent of the relationship between cogmotivational factors and academic learned helplessness among secondary school students in Rivers state.

The aim of this study was to investigate the extent cog-motivational factors, independently and collectively relate with academic learned helplessness of secondary school students in Rivers state. Specifically, the study addressed the following objectives:

1. Find out whether any relationship exists between self-efficacy and academic learned helplessness among secondary school students.

2. Find out the extent to which attribution relates with academic learned helplessness among secondary school students.

3. Examine whether achievement motivation relates with academic learned helplessness among secondary school students.

4. Establish whether cog-motivational factors of (self-efficacy, attribution and achievement motivation), collectively relate with academic learned helplessness among secondary school students.

The following research questions guided the study:

1. What is the relationship between self-efficacy and academic learned helplessness among secondary school students.

2. To what extent does attribution relate with academic learned helplessness among secondary school students.

3. What is the relationship between achievement motivation and academic learned helplessness among secondary school students.

4. To what extent do cog-motivational factors of (self-efficacy, attribution and achievement motivation), collectively relate with academic learned helplessness among secondary school students

The following null hypotheses guided the study and were tested at 0.05 level of significance:

1. There is no significant relationship between self-efficacy and academic learned helplessness among secondary school students.

2. There is no significant relationship between attribution and academic learned helplessness among secondary school students.

3. There is no significant relationship between achievement motivation and academic learned helplessness among secondary school students.

4. Cog-motivational factors of (self-efficacy, attribution and achievement motivation) collectively, do not significantly relate with academic learned helplessness.

This study will be of immense benefit to students, (especially the academic learned helpless students), because they will learn how to solve the problem of academic learned helplessness in their studies. It would enable school administrators to devise new strategies in teaching and learning, that will curb learned helplessness problem. It would also enable the government to see the need to employ trained counsellors in every public secondary school, to assist students who might develop learned helplessness problem to overcome it

\section{Methods}

This study adopted correlational design. The population of the study consist of all academic learned-helpless secondary schools two (SS2) students in the public senior secondary schools in Rivers state. As at the time of the study, there are 32,126 senior secondary two (SS2) students in public senior secondary schools in Rivers state. A sample of 500 academic learned helpless students was used for the study. Multi-stage sampling procedure was adopted for this study. Two instruments were used for this study, namely: Cog-motivational Factors Scale (CFS), and Academic Learned Helplessness Scale (ALHS).

The face, content and construct validities of the instruments were determined. The reliabilittes of the instruments were determined through the application of Cronbach Alpha technique and the results include: Selfefficacy 0.70, Attribution 0.69, Achievement motivation 0.83. The total mean reliability coefficient of Cogmotivational Factors Scale is 0.81 . The reliability coefficient obtained for Academic Learned Helplessness Scale is 0.82 .

Simple regression was used to answer research questions 1-3, while research question 4 was answered using multiple regression. Hypotheses 1-3 were tested using Analysis of variance (Anova) and t-test associated with regression analysis while hypothesis 4 was tested using Anova associated with multiple regression analysis.

\section{Results}

Results got after data analysis were presented in the tables below 
Table 1: Relationship between Self-efficacy and Academic learned helplessness

\begin{tabular}{|c|c|c|c|c|c|}
\hline Model $\mathrm{R}$ & R Square & \multicolumn{2}{|c|}{ Adjusted R Square } & \multicolumn{2}{|c|}{ Std. Error of the estimate } \\
\hline $1 \quad-0.040$ & 0.002 & 0.000 & \multicolumn{3}{|c|}{4.13419} \\
\hline \multicolumn{6}{|c|}{ Analysis of Variance (ANOVA) } \\
\hline & Sum of squares & df & Mean square & $\mathrm{F}$ & Sig \\
\hline Regression & 13.790 & & 113.790 & 0.807 & 0.369 \\
\hline Residual & 8511.592 & 498 & 17.092 & & \\
\hline \multirow[t]{2}{*}{ Total } & 8525.382 & 499 & & & \\
\hline & \multicolumn{2}{|c|}{$\begin{array}{c}\text { Unstandardized } \\
\text { Coefficients }\end{array}$} & \multicolumn{3}{|l|}{$\begin{array}{l}\text { Standardized } \\
\text { Coefficients }\end{array}$} \\
\hline Model & B & Std. Error & Beta & $\mathrm{t}$ & Sig \\
\hline constant & 24.875 & 0.875 & & 8.416 & 0.000 \\
\hline Self-efficacy & -0.025 & 0.028 & -0.040 & -0.808 & 0.369 \\
\hline
\end{tabular}

Dependent variable: Academic Learned Helplessness

The results in table 1 revealed that the $\mathrm{R}$ value obtained for self-efficacy and academic learned helplessness was 0.040. In view of this, self-efficacy had a low negative relationship with academic learned helplessness. To determine if the relationship is significant or not, analysis of variance (ANOVA) associated with the regression was employed. The calculated $\mathrm{F}$ value of 0.807 was significant at 0.369 , which is greater than the chosen level of probability of 0.05 , hence, the null hypothesis was accepted. In other to confirm the result further, t-test associated with the regression analysis was employed. It was observed that the Beta value for self -efficacy was -0.040 , associated t-value was 0.808 , significant at 0.369 , which is greater than the chosen level of probability $(0.05)$. Therefore, the null hypothesis of "self-efficacy does not significantly relate with academic learned helplessness" was accepted. This implies statistically that, self-efficacy does not have a significant relationship with academic learned helplessness.

Table 2: Relationship between Attribution and Academic learned helplessness

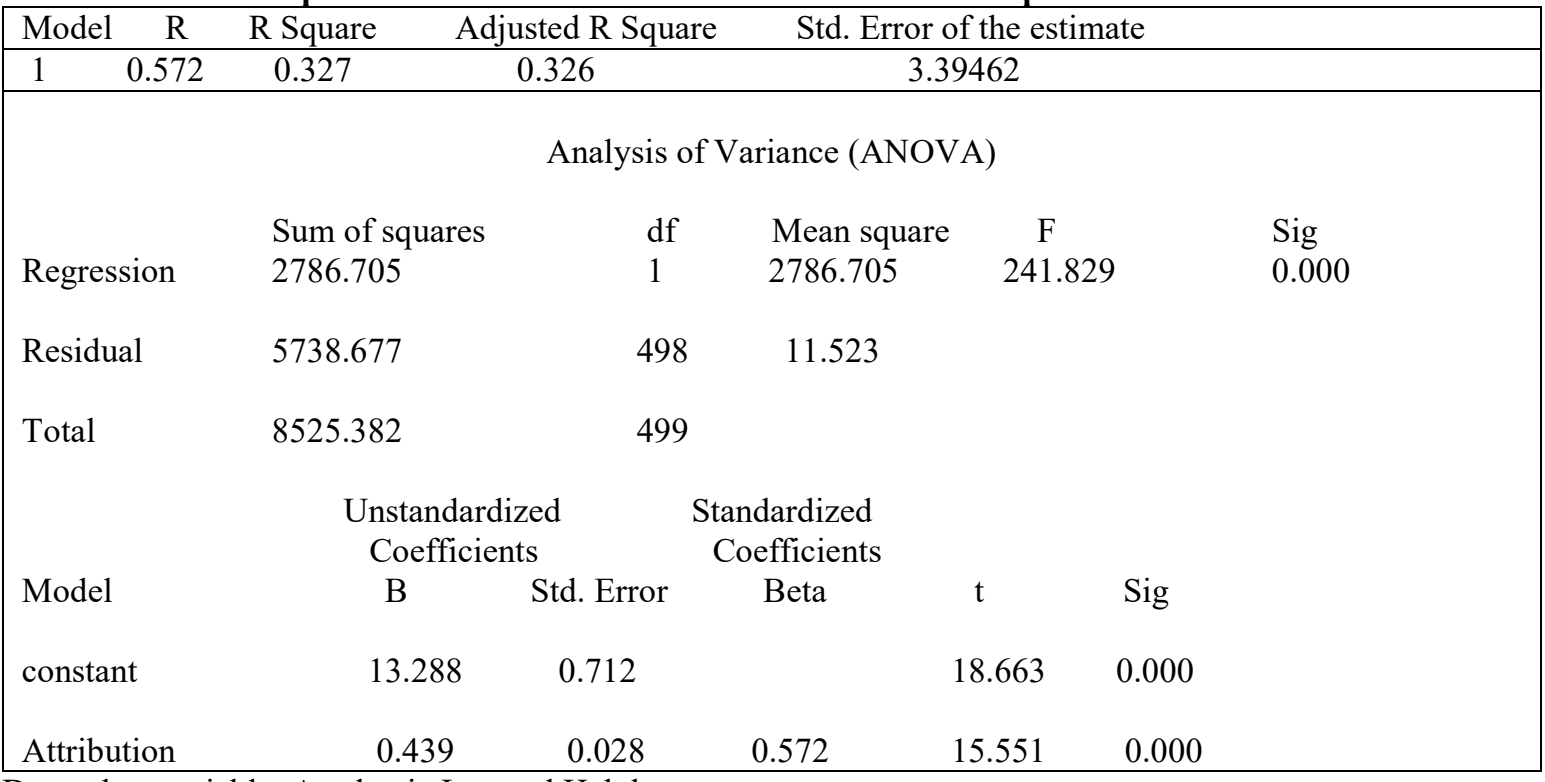

Dependent variable: Academic Learned Helplessness

The results in table 2 revealed that the $\mathrm{R}$ value for attribution and academic learned helplessness was 0.572 . In view of this, Attribution had a moderate positive relationship with academic learned helplessness. To determine if the relationship is significant or not, analysis of variance (ANOVA) associated with the regression was employed. The calculated $F$ value of 241.8290 was significant at 0.000 , which is less than the chosen level of probability of 
0.05 , hence the null hypothesis was rejected. To confirm the result further, t-test associated with the regression analysis was employed. It was observed that the Beta value for attribution 0.572, associated t-value for was 15.551, significant at 0.00 , which is less than the chosen level of probability (0.05). Therefore, the null hypothesis of "Attribution does not significantly relate with academic learned helplessness" was rejected. This implies statistically that, attribution actually has a significant relationship with academic learned helplessness.

Table 3: Relationship between Achievement Motivation and Academic learned helplessness

\begin{tabular}{|c|c|c|c|c|c|c|}
\hline Model & $\mathrm{R}$ & R Square & \multicolumn{2}{|c|}{ Adjusted R Square } & \multicolumn{2}{|c|}{ Std. Error of the estimate } \\
\hline 1 & 0.001 & 0.000 & \multicolumn{2}{|c|}{-0.002} & \multicolumn{2}{|c|}{4.13754} \\
\hline \multicolumn{7}{|c|}{ Analysis of Variance (ANOVA) } \\
\hline & & Sum of squares & df & Mean square & $\mathrm{F}$ & Sig \\
\hline Regressio1 & & 0.006 & 1 & 0.006 & 0.000 & 0.986 \\
\hline Residual & & 8525.376 & 498 & 17.119 & & \\
\hline \multirow{2}{*}{\multicolumn{2}{|c|}{ Total }} & 8525.382 & 499 & & & \\
\hline & & \multicolumn{2}{|c|}{$\begin{array}{c}\text { Unstandardized } \\
\text { Coefficients }\end{array}$} & \multicolumn{2}{|c|}{$\begin{array}{l}\text { Standardized } \\
\text { Coefficients }\end{array}$} & \\
\hline Model & & B & Std. Error & Beta & $\mathrm{t}$ & Sig \\
\hline constant & & 24.099 & 0.431 & & 55.888 & 0.000 \\
\hline $\begin{array}{l}\text { Achievem } \\
\text { Motivatior }\end{array}$ & $\begin{array}{l}\text { nent } \\
\text { on }\end{array}$ & 0.000 & 0.021 & 0.001 & 0.018 & 0.986 \\
\hline
\end{tabular}

Dependent variable: Academic Learned Helplessness

The results in table 3 revealed that the $\mathrm{R}$ value for Achievement motivation was 0.001 . In view of this, Achievement motivation had a very low positive relationship with academic learned helplessness. To determine if the relationship is significant or not, analysis of variance (ANOVA) associated with the regression was employed. The calculated $\mathrm{F}$ value of 0.000 was significant at 0.986 , which is greater than the chosen level of probability of 0.05 , hence the null hypothesis was accepted. In confirming the result further, t-test associated with the regression analysis was employed. It was observed that the Beta value for Achievement motivation was 0.001, associated tvalue was 0.018 , significant at 0.986 , which is greater than the chosen level of probability (0.05). Therefore, the null hypothesis of "Achievement motivation do not significantly relate with academic learned helplessness" was accepted. This implies statistically that, Achievement motivation does not have a significant relationship with academic learned helplessness.

Table 4: Multiple regression analysis of the joint relationship between the cog-motivational factors and academic learned helplessness

\begin{tabular}{|lccccc|}
\hline Model & $\mathrm{R}$ & $\mathrm{R}^{2}$ & Adjusted $\mathrm{R}^{2}$ & Std. Error of Estimate \\
\hline \multicolumn{7}{c}{ Analysis of Variance (ANOVA) } \\
\multicolumn{7}{c}{0.581} & 0.337 & 0.333 & 3.37506 \\
& Sum of squares & df & Mean square & F & Sig \\
Regression & 2875.415 & 3 & 958.472 & 84.142 & 0.000 \\
Residual & 5649.967 & 496 & 11.391 & \\
Total & 8525.382 & 499 & & \\
\hline
\end{tabular}

Dependent variable: Academic Learned Helplessness

Predictor variables: Self-efficacy, Attribution and Achievement motivation

The result in table 4 revealed the multiple regression analysis of the joint relationship of (Self-efficacy, Attribution and Achievement motivation) and Academic learned helplessness. The multiple regression coefficient obtained was 0.581 , the value of $\mathrm{R}^{2}$ was 0.337 while the adjusted coefficient of $\mathrm{R}^{2}$ obtained was 0.333 . This means that the three independent variables (Self-efficacy, Attribution and Achievement motivation) jointly had a moderate 
positive relationship with Academic learned helplessness. Based on the $\mathrm{R}^{2}$ value of 0.337 , it indicates that the joint relationship of the three independent variables only explain $33.7 \%$ of the variations in Academic learned helplessness while the remaining $66.3 \%$ may be due to other factors outside the scope of the study.

To determine if the relationship is significant or not, analysis of variance (ANOVA) associated with multiple regression was employed. The calculated $F$ value of 84.142 was significant at 0.000 level, which is less than the chosen level of probability of 0.05 , hence the null hypothesis is rejected. This implies that self-efficacy, attribution and achievement motivation collectively, significantly relate with academic learned helplessness among secondary school students.

\section{Discussion of Findings}

The discussion of findings of this study was based on the results of the research questions stated and the null hypotheses formulated and tested. Considering self-efficacy, the finding of this study showed that self-efficacy had a low negative relationship with academic learned helplessness. This relationship was found not significant at 0.05 levels of significance. This means that the higher the self-efficacy of an individual, the lower the tendency to experience academic learned helplessness. This finding is in agreement with the findings made by Sorrenti et al (2017), on learned helplessness and mastery orientation: the contribution of personality traits and academic beliefs. This study was conducted in the city of Messina in Sicily, Italy with a sample of 196 students from middle school, (111 males and 85 female). The results obtained after application of regression analysis on the data collected indicated that school self-efficacy correlate negatively with learned helplessness. The finding of this study was not in conformity with the study carried out by Valas (2001), on learned helplessness and psychological adjustment using Norwegian $10^{\text {th }}$-grade students on a sample of 1,580 students. The results obtained after application of multivariate analysis of variance and structural equation models showed that learned helplessness was significantly related with psychological adjustments (self-esteem and depression). The difference in the finding could be as a result of using a higher sample size than that used in the present study.

Secondly, the finding of this study showed that attribution had a moderate positive relationship with academic learned helplessness which was significant at 0.05 levels of significance. This implies that the higher the internal and stable attribution an individual has, the higher the tendency to experience academic learned helplessness. The finding of this study also is in conformity with the study carried out by Nolen-Hoeksema et al (1986), on learned helplessness in the classroom; a longitudinal study on depression, achievement and explanatory style. They used a sample of 168 elementary school children. The results indicated that a maladaptive explanatory style (internal/stable/global attribution) was significantly associated with more helpless behaviors in the classroom.

In the case of achievement motivation, this study found that achievement motivation had a very low positive relationship with academic learned helplessness which was tested not significant at 0.05 level of significance. This means that the higher scores in an individual's achievement motivation, indicates higher tendency to experience academic learned helplessness. This implies that excessively high achievement motivation leads to academic learned helplessness, thus a moderate achievement motivation level is encouraged. The result of this study is in agreement with the study carried out by Buys and Winefield (1981), on learned helplessness in high school students following experience of non-contingent rewards, using triadic design. They used a sample of 80 private secondary school students in South Australia. The findings indicated a strong helplessness effect in both high and low achievement motivational groups. The present study was also in agreement with the finding made by Jardine and Winefield (1983) on a study of achievement motivation, psychological reactance and learned helplessness, on a sample of 80 students. The study was conducted on high school students, using triadic design. They found interaction and facilitation between achievement motivation level and learned helplessness.

Finally, the finding of this study indicated that Cog-motivational factors of (self-efficacy, attribution and achievement motivation) jointly had a moderate positive relationship with academic learned helplessness. The relationship was significant at 0.05 levels of significance. This finding is in agreement with the finding made by Ekechukwu \& Isiguzo, (2015) on psychological factors associated with learned helplessness among adolescents. Results indicated that depression, locus of control and self-concept are associated with learned helplessness.

\section{Recommendations}

Based on the findings of this study, the following recommendations were made:

1. Students should be trained to inculcate high self-efficacy in their studies, which helps to reduce the problem of academic learned helplessness.

2. Internal, stable and global attribution style should be discouraged among the students, especially the academic learned helpless students, in order to reduce the problem of academic learned helplessness among students.

3. Students should be encouraged to maintain a moderate level of achievement motivation in their studies to avoid academic learned helplessness.

4. Finally, Guidance counselors should be employed in all public secondary schools in Rivers state, to help 
students with the problem of academic learned helplessness.

\section{Conclusion}

This study found that cog-motivational factors of (self-efficacy, attribution and achievement motivation) jointly, had a low positive relationship with academic learned helplessness.

Independently, self-efficacy had a negative relationship with academic learned helplessness, while attribution and achievement motivation had positive relationships with academic learned helplessness. Statistical testing revealed that independently, attribution had a significant relationship with academic learned helplessness while self-efficacy and achievement motivation had no significant relationship with academic learned helplessness. Therefore the problem of academic learned helplessness experienced by many students in Rivers state is a function of cog-motivational factors such as self-efficacy, attribution and achievement motivation.

\section{References}

Cherry, K. (2014).Learned helplessness: what it is and why it happens. Retrieved March 2018 from www.verywell.com $>$ living well $>$ an overview of psychology $>$ Glossary of psychology terms.

Durkin, K. (1995). Developmental social psychology: from infancy to old age. Malden, Massachusetts: Blackwell publishers inc.

Ekechukwu, R.O \& Isiguzo, B. C. (2015).Psychological factors associated with learned helplessness among secondary school adolescents. European Journal of Research and Reflection in Educational Sciences 3(4) 89-93.

Ekeh, P.U \& Nwanze, R.C.(2015).Personality traits as Correlates of learned helplessness among low Achieving students in mathematics. European Psychological Research 12(3);7-8.

Jardine, E \& Winefield, A. (1981). Achievement motivation level and treatment. Retrieved April 2, 2018 from link.springer.com/....BF00992898.

Nolen-Hoeksema, S., Seligman, M.E.P \& Girgus, J.S (1986). Learned helplessness in children: A longitudinal study of Depression, Achievement and Explanatory style. Journal of Personality and Social Psychology $51(2), 435-442$.

Nwankwo, O.C. (2013). A practical guide to research writing: for students in education and social sciences. Port Harcourt: Pam unique publishers.

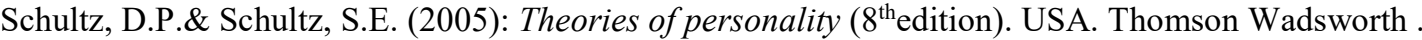

Sorrenti, L., Fillipello, P., Buzzai, C., Butto, C., and Costa, S. (2017). Learned helplessness and mastery orientation: The contribution of personality traits and academic beliefs. Journal of Nordic Psychology $70(1), 71-84$

Valas, H. (2001). Learned helplessness and psychological adjustment. Scandinavian Journal of Educational Research 45(1),429.

Winefield, A.H. (1983). Cognitive performance deficits induced by exposure to response - independent positive outcomes. Motivation and Emotion 7(2), 145-155. 